\title{
Some Factors Affecting the Surface Area of Hydrated Portland Cement as Determined by Water-Vapor and Nitrogen Adsorption
}

\author{
L. A. Tomes, ${ }^{1}$ C. M. Hunt, and R. L. Blaine
}

\begin{abstract}
Brunauer-Emmett-Teller (BET) surface areas of hydrated portland cement have been calculated from water-vapor and nitrogen-adsorption data. The adsorption and desorption of water vapor caused measurable decreases in specific surface areas by both water-vapor and nitrogen adsorption. Changes were also produced by wetting and drying. The adsorption and desorption of nitrogen at the boiling point of liquid nitrogen did not produce similar effects.

The specific surface and nonevaporable-water content of a hydrated cement are also somewhat dependent on the initial drying treatment. The effect of measuring water-vapor surface and nonevaporable water with specimens dried for different periods of time is also considered.
\end{abstract}

\section{Introduction}

Measurements of water vapor $[1,2,3 \mathrm{a}, 3 \mathrm{~b}, 4]^{2}$ and nitrogen sorption $[4,5]$, as well as other evidence $[6,7]$, have demonstrated that the hydration products of portland cement are largely colloidal in nature. Powers and Brownyard [3a, 3b] have carried out water-vapor adsorption measurements on a number of hydrated cements and found that $v_{m}$, the parameter in the Brunauer-Emmett-Teller (BET) equation [8], from which a value for specific surface is calculated, was proportional to $w_{n}$, the nonevaporable-water content of the hydrated cement. They found the ratio of $v_{m} / w_{n}$ to be relatively constant and not greatly affected by the age or water-cement ratio of the spcimen. The constant proportionality between $v_{m}$ and $w_{n}$ indicates that surface computed from water-vapor adsorption data is proportional to the amount of hydration products present. This evidence suggests that some kind of structural similarity exists between the hydration products formed during the first few days of hydration, and those formed during the later stages of hydration [3a].

Although the constant $v_{m} / w_{n}$ ratio for specimens made from a given cement provides an important clue in determining the submicroscopic morphology of hydrated portland cement, both $v_{m}$ [9] and $w_{n}$ $[3 \mathrm{a}, 9,10]$ are somewhat dependent upon the arbitrary conditions under which they are determined. For example, it was noted by Powers and Brownyard [3a] that successive sorption isotherms by the same specimen of hardened cement paste were not reproducible, a fact that suggests strong interaction between water vapor and one or more of the hydration products of cement. Thus, whereas specific surface is a function of the amount of hydration products present, nonreversible sorption behavior suggests that it also depends on the history of a specimen after hydration has stopped. The present

${ }^{1}$ Research Associate representing the Calcium Chloride Institute at the National Bureau of Standards.

${ }^{2}$ Figures in brackets indicate the literature references at the end of this paper. paper considers the nonreversible sorption behavior of hydrated cement and gives further examples that illustrate the effect of wetting or exposure to water vapor upon subsequent adsorption of water vapor by hardened cement paste. Nitrogen-adsorption measurements have also been made as an independent method of detecting small changes in the colloidal structure of hydrated cement.

Another factor to be considered in the determination of $v_{m}$ and $w_{n}$ is the difficulty of determining how much of the water in a hardened cement is chemically combined [3a, 9, 10, 11]. However, by carefully controlling the conditions of drying, it is possible to obtain a reproducible but arbitrary dry weight, which affords a baseline from which to determine $v_{m}$ and $w_{n}$. Powers and Brownyard $[3 \mathrm{a}, 3 \mathrm{~b}]$ have determined these quantities after drying hardened cement paste in a vacuum system containing magnesium perchlorate dihydrate and tetrahydrate, whereas Copeland and Hayes [9] have described a procedure for vacuum-drying cement pastes, which uses a dry-ice trap in the system to establish the water-vapor concentration. According to Copeland and Bragg [12], nonevaporable water in specimens dried by this latter procedure probably corresponds rather closely to chemically combined water. However, hardened cement pastes and hydrated calcium silicates reach constant weight almost asymptotically when dried in vacuum at room temperature. It is common practice to discontinue drying while the specimens are still losing weight at a very small but detectable rate $[9,13]$. Therefore, this paper also considers the manner in which $v_{m}$ and $w_{n}$ vary when they are determined on specimens of the same paste that have been dried for different periods of time.

\section{Methods and Materials}

\subsection{Water-Vapor and Nitrogen Adsorption Measurements}

Two types of water-vapor sorption apparatus were used in these experiments, a vacuum apparatus 
similar to the McBain-Bakr Balance [14], and a gas-stream apparatus. The essential features of the vacuum apparatus, including one of its six quartz springs, is illustrated in figure 1. The apparatus could accommodate specimens weighing 0.4 to 0.8 g. Spring extensions were measured with an external cathetometer. The gas-stream apparatus, illustrated in figure 2, was similar to the one described by Powers and Brownyard [3a]; however, it used nitrogen instead of air to transport the water vapor. Five-gram specimens were used with this apparatus, although it could handle much larger specimens. Five to seven days were allowed for sorption equilibrium with the gas-stream apparatus, whereas $24 \mathrm{hr}$ were allowed with the vacuum ap-

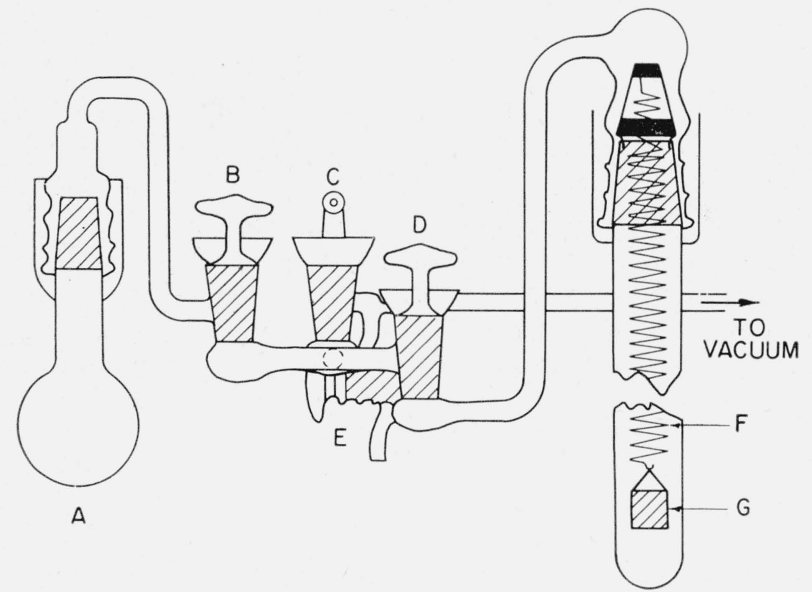

Figure 1. Side view of apparatus for measuring water-vapo? sorption in vacuum.

Solutions used and relative vapor pressures [15] are: Sodium hydroxide, 0.0703; lithium chloride, 0.1105 ; potassium acetate, 0.2245 ; magnesium chloride, 0.3300 , lithium chloride, 0.1105 ; potassium acetate, 0.2245 ; magnesium chloride, 0.3300 . A, Flask containing saturated solution for establishing water-vapor pressure;
B, stopcock for isolating solution flask; C, stopcock to vacuum pump; D, stopcock for isolating specimen tubes; E, stopcock for admitting air to apparatus; F, quartz spring; $\mathrm{G}$, specimen bucket.

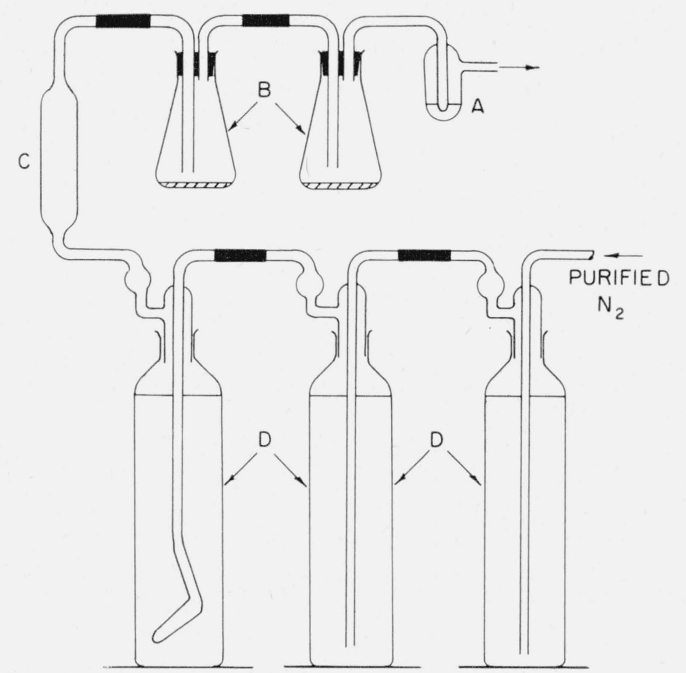

FIGURE 2. Sorption train for exposing specimens to controlled water-vapor concentrations.

A, Bubble counter containing mineral oil; B, 125-ml Erlenmeyer'flasks containing specimens; C, glass wool trap; D, sulfuric acid solutions for establishing water vapor pressure. paratus. Exposure of hardened cement pastes for longer periods of time at these relative humidities has indicated that very little additional water was taken up, and a few specimens actually lost weight, a behavior previously noted by Powers and Brownyard [3a]. Both the vacuum and gasstream apparatus were operated in a cabinet maintained at $25.0^{\circ} \pm 0.1^{\circ} \mathrm{C}$.

Specimens were vacuum dried in an apparatus similar to the one described by Copeland and Hayes [9], in which a trap maintained at the temperature of dry ice was placed between the specimens and the pump. The system maintained a vacuum of about $2 \mu$ of mercury in the final stages of drying, and it was operated in a room maintained at $21^{\circ} \mathrm{C}$. The vapor pressure of water at $-78^{\circ} \mathrm{C}$ is $0.56 \mu$. When the vacuum apparatus illustrated in figure 1 was used, final drying and water-vapor adsorption measurements were carried out in the same apparatus.

Values of $v_{m}$ were calculated by the BET equation [8],

$$
\frac{p}{v\left(p_{0}-p\right)}=\frac{1}{v_{m} C}+\frac{C-1}{v_{m} C} p / p_{0}
$$

where $p$ is the pressure of water vapor in equilibrium with the specimen, $p_{0}$ is the vapor pressure of pure water, $C$ is a constant related to the heat of adsorption, and $v$ is the amount of water adsorbed per gram of specimen. Because the adsorption of water was measured gravimetrically, $v$ and $v_{m}$ have been expressed in grams of water per gram of specimen. To compute surface areas, an area coverage of $10.6 \mathrm{~A}^{2}$ was assumed for the water molecule.

Nitrogen adsorption measurements were made with an apparatus similar to that described by Emmett [16]. Specimens were outgassed overnight at $100^{\circ}$ to $110^{\circ} \mathrm{C}$ before measuring their nitrogen adsorption. Surface areas were calculated, assuming each molecule to cover an area of $16.2 \mathrm{~A}^{2}$.

\subsection{Nonevaporable Water Determination}

The values for nonevaporable water appearing in figure 6 were determined by igniting the specimens to constant weight at $1,050^{\circ} \mathrm{C}$ after they were vacuum dried in a system containing a trap at the temperature of dry ice. This is essentially the procedure of Copeland and Hayes [9], except that drying time has been purposely made variable. The nonevaporable water differs from the loss on ignition by an amount equal to the ignition loss of the original cement. As Powers and Brownyard have pointed out [3a], there is some uncertainty in this correction, which means that the absolute values of nonevaporable water are known with less certainty than the relative values.

\subsection{Preparation of Specimens}

Neat cement pastes, having a water-cement ratio of 0.5 , were prepared in a mechanical mixer and cast in the form of square wafers $1 \mathrm{~cm}$ thick and $5 \mathrm{~cm}$ on 
each side. The specimens were removed from the molds after $24 \mathrm{hr}$ and cured in closed quart jars in the presence of high concentrations of water vapor for periods indicated in the experiments. To stop hydration, the specimens were vacuum dried for 2 days. They were broken into smaller pieces and stored several months in sealed glass tubes before sampling. In this way, storage changes were not taking place at a significant rate at the start of the experiments.

The chemical composition of the clinker and the cement from which the pastes were prepared is given in table 1.

TABLE 1. Composition of cement clinker a

\begin{tabular}{|c|c|c|c|}
\hline \multirow{2}{*}{ Oxide } & \multirow{2}{*}{$\begin{array}{l}\text { Percentage } \\
\text { by weight }\end{array}$} & \multicolumn{2}{|c|}{$\begin{array}{l}\text { Calculated composition, } \\
\text { percentage by weight } \mathrm{b}\end{array}$} \\
\hline & & Composition & Percentage \\
\hline $\begin{array}{l}\mathrm{CaO} \\
\mathrm{SiO}_{2} \\
\mathrm{Al}_{2} \mathrm{O}_{3} \\
\mathrm{Fe}_{2} \mathrm{O}_{3} \\
\mathrm{SO}_{3} \\
\mathrm{MgO} \\
\mathrm{Na} \mathrm{O}_{2} \\
\mathrm{~K}_{2} \mathrm{O} \\
\mathrm{Loss} \text { on ignition a } \\
\text { Insoluble residue }\end{array}$ & $\begin{array}{r}65.13 \\
22.62 \\
4.41 \\
5.33 \\
0.10 \\
1.71 \\
0.04 \\
.28 \\
.37 \\
.14\end{array}$ & $\begin{array}{l}3 \mathrm{CaO} \cdot \mathrm{SiO}_{2} \\
3 \mathrm{CaO} \cdot \mathrm{Al}_{2} \mathrm{O}_{3} \\
4 \mathrm{CaO} \cdot \mathrm{Al}_{2} \mathrm{O}_{3} \cdot \mathrm{Fe}_{2} \mathrm{O}_{3} \\
2 \mathrm{CaO} \cdot \mathrm{SiO}_{2}\end{array}$ & $\begin{array}{r}56 \\
3 \\
16 \\
23\end{array}$ \\
\hline
\end{tabular}

a This elinker was interground with gypsum and blended to a 1.8-percent $\mathrm{SO}_{3}$ content. The ignition loss of the blended cement at $1,050^{\circ} \mathrm{C}$ was 1.69 percent. b Composition calculated from equations found in Bogue, The Chemistry of Portland Cement, p. 548 (Reinhold Publishing Co., Inc., New York, N. Y., 1947). The values represent potential composition at equilibrium crystallization.,

\section{Results}

\subsection{Sorption and Desorption of Water Vapor}

Table 2 gives the amounts of water adsorbed by two specimens of paste which were subjected to several cycles of drying and exposure to water vapor. The experiment was carried out in the apparatus illustrated in figure 1 . The specimens were dried 6 days from the stored state before initial exposure to water vapor. In cycles 2 through 7 the specimens were redried as nearly as possible to their cycle 1 dry weight before exposure to water vapor. When dried in this way, permanent loss of chemically combined water would appear in table 2 as a decrease in the amount of water adsorbed, because all of the sorption sites initially available would not be uncovered by redrying specimens to their initial dry weight. In cycle 8 , however, the specimens were dried 41 days, so that any initially available sites would be uncovered, unless the specimens had undergone change during the experiment.

It may be seen from table 2 that the specimens adsorbed less water with each repeated exposure to water vapor for the first 4 or 5 cycles. Thereafter, the effects were less marked. This is illustrated in another way in figure 3 , where calculated surface areas have been plotted for each cycle of drying and humidification. In the eighth cycle, after the 41-day drying treatment, slightly more water was adsorbed than in the preceding cycle, but the original sorptive capacity of the specimens was never regained. The
TABLE 2. Amounts of water adsorbed by cement paste during several cycles of drying and adsorption

\begin{tabular}{|c|c|c|c|c|c|}
\hline \multirow[t]{2}{*}{ Specimen a } & \multirow[t]{2}{*}{ Cycle } & \multicolumn{4}{|c|}{$\begin{array}{l}\text { b Grams of water adsorbed per gram of } \\
\text { dry paste at relative vapor pressure } \\
\left(p / p_{0}\right)-\end{array}$} \\
\hline & & 0.0703 & 0.1105 & 0.2245 & 0.3300 \\
\hline $\begin{array}{l}\text { 1. Lumps of paste } 5 \text { to } \\
8 \mathrm{~mm} \text { in diameter- }\end{array}$ & $\begin{array}{l}1 \\
2 \\
3 \\
4 \\
5 \\
6 \\
7 \\
8\end{array}$ & $\begin{array}{l}0.0214 \\
.0190 \\
.0178 \\
.0169 \\
.0154 \\
.0159 \\
.0155 \\
.0165\end{array}$ & $\begin{array}{r}0.0249 \\
.0215 \\
.0201 \\
.0190 \\
.0183 \\
.0182 \\
.0174 \\
.0192\end{array}$ & $\begin{array}{r}0.0314 \\
.0271 \\
.0248 \\
.0236 \\
.0225 \\
.0218 \\
.0211 \\
.0228\end{array}$ & $\begin{array}{r}0.0355 \\
.0308 \\
.0283 \\
.0266 \\
.0256 \\
.0248 \\
.0242 \\
.0257\end{array}$ \\
\hline $\begin{array}{l}\text { 2. Pulverized paste } \\
\text { less than } 1 \mathrm{~mm} \text { in } \\
\text { diameter }\end{array}$ & $\begin{array}{l}1 \\
2 \\
3 \\
4 \\
5 \\
6 \\
7 \\
8\end{array}$ & $\begin{array}{l}.0229 \\
.0196 \\
.0173 \\
.0169 \\
.0146 \\
.0157 \\
.0140 \\
.0152\end{array}$ & $\begin{array}{l}.0262 \\
.0231 \\
.0198 \\
.0193 \\
.0172 \\
.0176 \\
.0158 \\
.0175\end{array}$ & $\begin{array}{l}.0325 \\
.0273 \\
.0241 \\
.0229 \\
.0210 \\
.0210 \\
.0193 \\
.0209\end{array}$ & $\begin{array}{l}.0364 \\
.0308 \\
.0271 \\
.0260 \\
.0238 \\
.0233 \\
.0220 \\
.0230\end{array}$ \\
\hline
\end{tabular}

a The specimens were obtained from paste that was cured in moist air for week. Specimen 1 weighed $0.6636 \mathrm{~g}$ and specimen 2 weighed $0.7181 \mathrm{~g}$ in their dryest state (cycle 8).

$\mathrm{b}\left(w-w_{d}\right) / w_{d} ; w=$ weight of conditioned specimen, $w_{d}=$ dry weight of specimen for respective eycle, and $w_{d 8}=$ dry weight of specimen for cycle 8 .

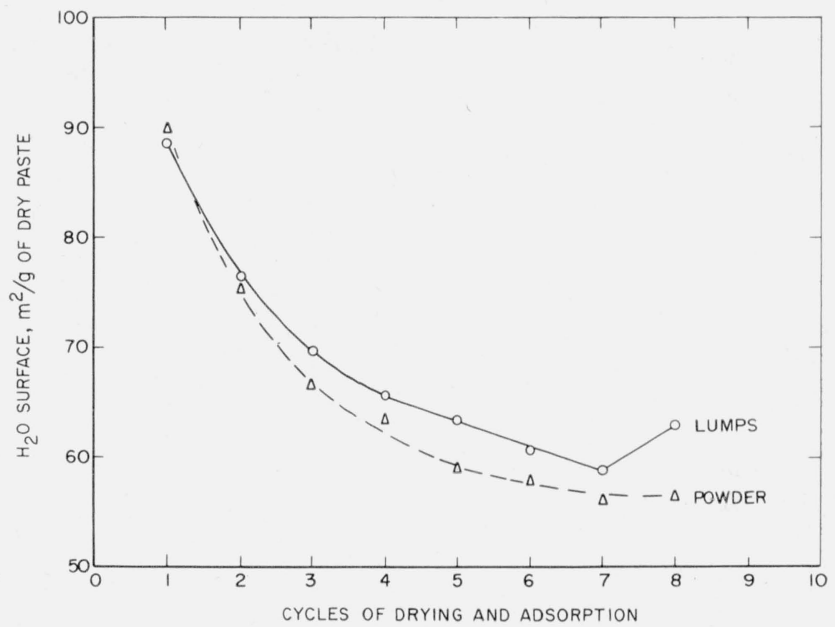

FIGURE 3. Specific surface by water-vapor adsorption obtained by repeated measurement of the same specimens of hardened cement paste.

dry weight of the specimens did not decrease by more than 2 to $3 \mathrm{mg}$ per gram of paste between the seventh and eighth cycles. There may be uncertainties in this estimate, due to gain of small amounts of carbon dioxide or other atmospheric contaminants during the course of the experiment, but the change in dry weight could be much larger than 2 to $3 \mathrm{mg}$ and still be too small to account for change in nonevaporable water proportional to the change in computed surface. Therefore, the loss in sorptive capacity probably involves small changes in the colloidal structure of the paste.

The first specimen in table 2 consisted of lumps of hardened paste 5 to $8 \mathrm{~mm}$ in diameter, whereas the second specimen was crushed in an atmosphere of nitrogen until most of it was reduced to a powder much finer than the 1-mm upper limit given in the table. Comparison of the results obtained with 
these two specimens shows them to be slightly different. However, it is evident that the amount of water adsorbed and the change in sorptive capacity during the course of the experiment was not extremely dependent on the state of subdivision of the specimens.

Surface areas determined by nitrogen adsorption also showed the effect of exposure to water vapor. In table 3 , surface values are given for specimens that were measured after initial drying, and specimens that were exposed to water vapor at relative humidities up to 24 percent and redried. The redried specimens had smaller surfaces, affording independent evidence of change in the colloidal structure of the paste. There is no evidence that the adsorption and desorption of nitrogen at low temperatures brought about changes similar to those produced with water vapor.

TABLE 3. Effect of adsorption and desorption of water vapor on the nitrogen surfaces of cement pastes

\begin{tabular}{|c|c|c|c|c|}
\hline \multirow[t]{2}{*}{ Curing time } & \multicolumn{2}{|c|}{$\begin{array}{l}\text { Measured after } \\
\text { initial drying }\end{array}$} & \multicolumn{2}{|c|}{$\begin{array}{l}\text { Measured after adsorp } \\
\text { tion and desorption } \\
\text { of water vapor }\end{array}$} \\
\hline & Specimen a & Surface & Specimen a & Surface \\
\hline $\begin{array}{l}1 \text { day } \\
1 \text { day } \\
1 \text { week } \\
1 \text { week } \\
1 \text { month. } \\
1 \text { month }\end{array}$ & $\begin{array}{l}3 \mathrm{~A} \\
3 \mathrm{~B} \\
4 \mathrm{~A} \\
4 \mathrm{~B} \\
5 \mathrm{~A} \\
5 \mathrm{~B}\end{array}$ & $\begin{array}{l}m^{2} g \\
19.6 \\
18.0 \\
19.9 \\
18.5 \\
21.8 \\
21.8\end{array}$ & $\begin{array}{l}3 \mathrm{C} \\
3 \mathrm{D} \\
4 \mathrm{C} \\
4 \mathrm{D} \\
5 \mathrm{C} \\
5 \mathrm{D}\end{array}$ & $\begin{array}{l}m^{2} g \\
11.4 \\
15.9 \\
16.1 \\
17.5 \\
18.0\end{array}$ \\
\hline
\end{tabular}

a The A, B, C, and D specimens were taken from the same sample of hardened paste, which was not blended to produce uniformity as were samples in the ensuing experiments.

\subsection{Wetting and Drying}

Because the adsorption and desorption of water vapor resulted in changes in hydrated cement, the effect of wetting and drying was also investigated. Table 4 gives the amount of water vapor adsorbed by three specimens of paste, one of which was measured after the initial drying, and the others after rewetting and redrying. The experiment was performed with 5-g specimens, and adsorption measurements were made with the apparatus illustrated in figure 2. Rewetting and redrying were accomplished by covering the specimens with water for $1 \mathrm{hr}$ at $21^{\circ} \pm 2^{\circ} \mathrm{C}$ and carefully reevaporating the water in vacuum. The entire operation was performed in the adsorption flasks, so that any extracted material would be redeposited with the specimens. The results in table 4 have been expressed in grams of water adsorbed per gram of ignited paste, to permit closer comparison of different specimens. The paste from which these specimens were obtained was crushed and carefully blended before sampling. Analysis of data from 35 hardened pastes has shown that the amount of water adsorbed by different specimens from the same blended paste can be determined with a standard deviation of 0.3 mg per gram of ignited paste. This reproducibility indicates that the results in table 4 are highly significant.
TABLE 4. Effect of wetting and drying on the subsequent adsorption of water vapor by a dried cement paste

\begin{tabular}{|c|c|c|c|c|c|}
\hline \multirow[t]{2}{*}{ Specimen a } & \multirow{2}{*}{$\begin{array}{l}\text { Number } \\
\text { of times } \\
\text { wet and } \\
\text { dried }\end{array}$} & \multicolumn{4}{|c|}{$\begin{array}{l}\text { Grams of water adsorbed per gram of } \\
\text { ignited paste at relative vapor pres- } \\
\text { sure }\left(p / p_{0}\right)-\end{array}$} \\
\hline & & 0.0980 & 0.1462 & 0.1946 & 0.2380 \\
\hline $\begin{array}{l}6 \mathrm{~A} \\
6 \mathrm{~B} \\
6 \mathrm{C}\end{array}$ & $\begin{array}{l}0 \\
1 \\
3\end{array}$ & $\begin{array}{r}0.0275 \\
.0265 \\
.0255\end{array}$ & $\begin{array}{r}0.0304 \\
.0293 \\
.0276\end{array}$ & $\begin{array}{r}0.0327 \\
.0316 \\
.0297\end{array}$ & $\begin{array}{r}0.0348 \\
.0336 \\
.0314\end{array}$ \\
\hline
\end{tabular}

a These specimens were obtained from paste that was cured in moist air for 1 week.

Comparison of table 4 with table 2 shows that wetting and drying produced less change in watersorptive capacity than was produced by adsorption and desorption of water vapor. This difference suggests that the adsorption and desorption process may have occurred in a relative bumidity range where shrinkage effects predominated, whereas wetting and drying produced strong swelling and shrinking during each cycle.

The nitrogen surface was larger after a single rewetting, but smaller after the process was repeated two more times. The results are given in table 5 . It is believed that these changes do not represent a spurious effect, because they could be produced with other pastes. The change in water-vapor surface after a single rewetting was quite small, as shown in table 5. This suggests that a small shrinkage of the

TABLE 5. Comparison of water vapor and nitrogen surface areas of cement pastes, showing the effects of wetting and drying

\begin{tabular}{|c|c|c|c|c|}
\hline \multirow{2}{*}{$\begin{array}{c}\text { Number of times wet } \\
\text { and dried }\end{array}$} & \multicolumn{2}{|c|}{ Water vapor } & \multicolumn{2}{|c|}{ Nitrogen } \\
\cline { 2 - 3 } & Specimen a & Surface b & Specimen a & Surface b \\
\hline & & & & $m^{2} / g$ \\
& $6 \mathrm{~A}$ & 97.7 & $6 \mathrm{D}$ & 12.7 \\
& $6 \mathrm{~B}$ & 94.5 & $6 \mathrm{E}$ & 23.2 \\
& $6 \mathrm{C}$ & 87.3 & $6 \mathrm{~F}$ & 10.5 \\
\hline
\end{tabular}

a These specimens were obtained from paste that was cured in moist air for 1 week.

Specific surface based on ignited weight of paste.

regions accessible to water may increase the size or number of channels accessible to nitrogen, whereas further shrinkage reduces accessibility to both water vapor and nitrogen. Another possible explanation of the changes in nitrogen surface is that most of the water-soluble materials would probably be dissolved from the pores of the paste during the first rewetting, whereas in subsequent wetting and drying the watersoluble materials have already been removed and the shrinkage effect would predominate. It seems reasonable that water-vapor sorption would be relatively unaffected by the presence or absence of watersoluble materials in the pores of the paste.

It was anticipated that wetting the specimens would lead to further hydration, because they were covered with water for $1 \mathrm{hr}$ before drying was started. However, they redried to weights that were 2 parts per thousand less than the original dry weight, and 
the effect was very reproducible from specimen to specimen. It was doubtful if additional hydration took place during wetting, but if it did, it was completely obscured by structural changes which facilitated drying.

\section{3. $v_{m}$ and $w_{n}$ as Functions of Drying Time}

$v_{m}$ and $w_{n}$ were determined on specimens that were dried for different periods of time. Due to interaction between water vapor and hydrated cement as indicated in the preceding experiments, it was necessary to take a separate specimen for each drying time. The specimens were prepared from a single carefully blended sample of pulverized hydrated cement paste, and each specimen weighed about $5 \mathrm{~g}$. The results, which include drying time, dry weight, and amount of water adsorbed, are given in table 6 . All weights are expressed in grams per gram of ignited cement in order to compare data from different specimens. It may be seen from table 6 that the specimens which received longer drying treatments adsorbed more water. Values of $v_{m}$ and $w_{n}$ were determined for each specimen and plotted as functions of drying time in figure 4. It is evident that after a week of drying, the rates of change of $v_{m}$ and $w_{n}$ were small.

TABLE 6. Dry weights and amounts of water adsorbed by specimens dried for different periods of time

\begin{tabular}{|c|c|c|c|c|c|c|}
\hline \multirow[t]{2}{*}{ Specimen a } & \multirow{2}{*}{$\begin{array}{l}\text { Cumula- } \\
\text { tive dry- } \\
\text { ing time b }\end{array}$} & \multirow{2}{*}{$\begin{array}{l}\text { Dry } \\
\text { weight, } \\
\text { grams per } \\
\text { gram of } \\
\text { ignited } \\
\text { paste }\end{array}$} & \multicolumn{4}{|c|}{$\begin{array}{l}\text { Grams of water adsorbed per gram of ig- } \\
\text { nited paste at relative vapor pressure } \\
\left(p / p_{0}\right)-\end{array}$} \\
\hline & & & 0.0999 & 0.1478 & 0.1954 & 0.2400 \\
\hline $\begin{array}{l}7 \mathrm{~A} \\
7 \mathrm{~B} \\
7 \mathrm{C} \\
7 \mathrm{D}- \\
7 \mathrm{E} \\
7 \mathrm{~F}- \\
7 \mathrm{G}- \\
\end{array}$ & $\begin{array}{r}\text { Days } \\
2.6 \\
3.5 \\
4.4 \\
5.4 \\
6.4 \\
8.2 \\
12.1\end{array}$ & $\begin{array}{l}1.1373 \\
1.1234 \\
1.1186 \\
1.1171 \\
1.1155 \\
1.1145 \\
1.1126\end{array}$ & $\begin{array}{r}0.0147 \\
.0233 \\
.0254 \\
.0259 \\
.0264 \\
.0273 \\
.0283\end{array}$ & $\begin{array}{r}0.0172 \\
.0259 \\
.0285 \\
.0289 \\
.0294 \\
.0303 \\
.0312\end{array}$ & $\begin{array}{r}0.0192 \\
.0284 \\
.0304 \\
.0314 \\
.0320 \\
.0329 \\
.0336\end{array}$ & $\begin{array}{r}0.0214 \\
.0305 \\
.0329 \\
.0336 \\
.0341 \\
.0349 \\
.0359\end{array}$ \\
\hline
\end{tabular}

a These specimens were obtained from paste that was cured in moist air for 1 week.

b Includes 2 days of predrying the unground paste to stop hydration.

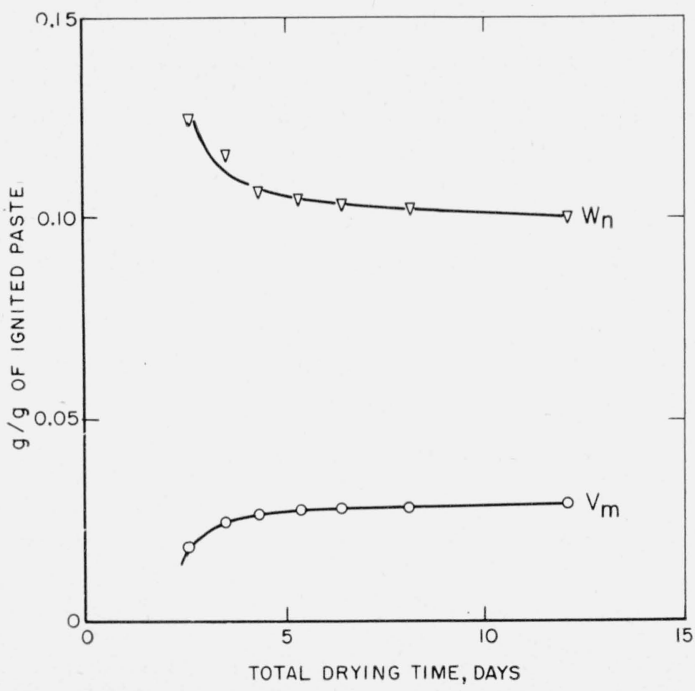

Figure $4 . v_{m}$ and $w_{n}$ as functions of drying time.

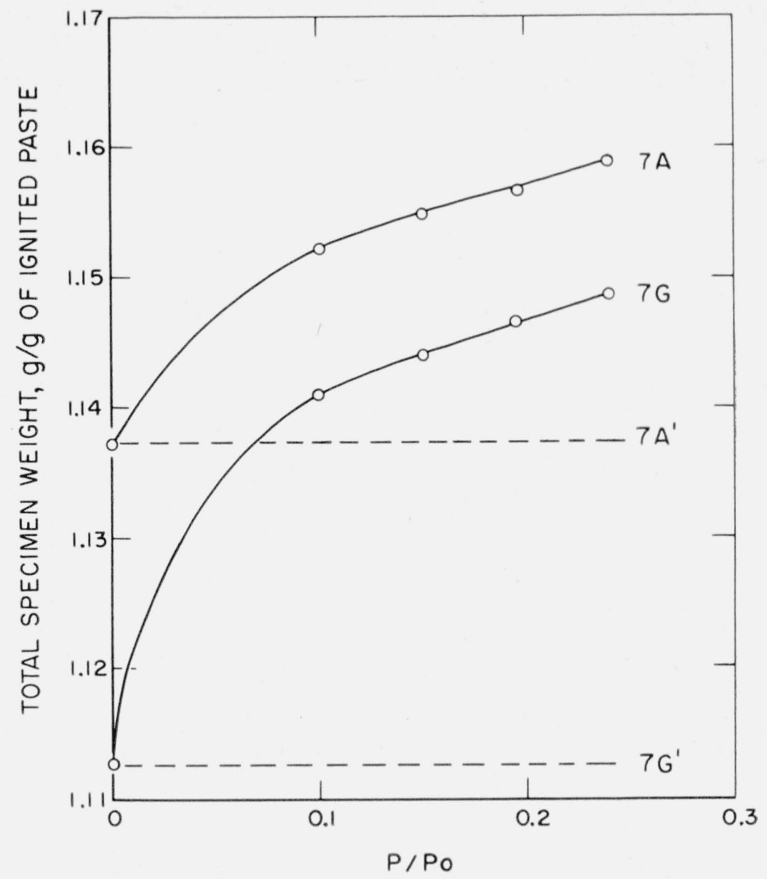

FIGURE 5. Adsorption isotherms up to 24-percent relative humidity of two specimens of the same cement paste dried to different levels of dryness.

The dotted lines represent the dry weights of the specimens and the curves represent the specimen weights after exposure to water vapor.

What is not immediately evident from the values in table 6 , however, is the fact that the specimens did not resorb all of the water that was removed in the latter stages of drying. It can be readily shown that differences in the amount of water adsorbed by any two specimens at the same relative humidity are smaller than the differences in their respective dry weights. Failure to regain all of this weight may be illustrated in another way. Using data from table 6 , the adsorption isotherms for specimens $7 \mathrm{~A}$ and $7 \mathrm{G}$ up to 24 percent relative humidity are plotted in figure 5. The amount of water adsorbed has been added to the dry weight, and the values so obtained are plotted as a function of relative vapor pressure. The horizontal dotted lines $7 \mathrm{~A}^{\prime}$ and $7 \mathrm{G}^{\prime}$ represent the dry weights per gram of ignited paste. It is evident that the isotherm for specimen $7 \mathrm{G}$, which was dried much longer than specimen $7 \mathrm{~A}$, did not retrace the $7 \mathrm{~A}$ isotherm. The isotherms were completed in about 40 days, and there is no evidence from the rates at which they gained weight that the two specimens would have reached the same weight in a much longer period.

\section{Discussion}

The water molecule, by virtue of its small molecular size and polar nature, is able to penetrate into colloidal domains of many adsorbents to which nitrogen cannot penetrate. This is true of hydrated cement, as shown by the results of Gleysteen and Kalousek [4], as well as the values given in table 5 . 
The polar and reactive nature of the water molecule raises some question as to the mechanism of sorption where certain adsorbents are involved $[17,18,19,20]$. This may also be true of hydrated portland cement. However, Bogue [6] has briefly reviewed evidence that the surface area of hydrated cement, by watervapor adsorption, is of the magnitude to be expected from electron microscope and low-angle X-ray scattering measurements. For the purposes of the present discussion, it is not essential that either the water vapor or nitrogen surface represent absolute surface values, to bring out the structurally significant fact that water vapor has access to sorption sites in hydrated portland cement that are inaccessible to nitrogen, or to investigate a few of the factors affecting the magnitude and reproducibility of surface values obtained.

The present paper considers some characteristics of hydrated cement which are important in the design and interpretation of gas and vapor adsorption experiments. They illustrate some of the problems involved in the determination of specific surface and nonevaporable water, and they also suggest that exposure to water or water vapor should not be one of the unintentional or uncontrolled variables in an experiment.

The isotherms of Powers and Brownyard [3a], mentioned in the early part of this paper, were measured at relative vapor pressures extending from dryness to slightly less than saturation pressure, and the specimens showed permanent gain in weight when redried. They attributed differences in successive isotherms to irreversible shrinkage at low relative humidity and additional hydration at relative humidities greater than 80 percent. In the present experiments, the specimens were not exposed to relative humidities greater than 33 percent, except those that were rewet and redried. Furthermore, it was possible to redry all specimens to weights close to their original dry weights. In this connection, Powers [21] has presented data showing that the hydration of an unhydrated cement was virtually unmeasureable when the cements were stored at relative humidities below 30 percent. He also found that hydration was slight unless the cement was exposed to relative humidities greater than 70 percent. Thus, in the present experiments, changes in specific surface of the order of 10 to 30 percent of the initial value were produced with little if any change in the degree of hydration.

The changes in surface and $v_{m}$ obtained here might be predicted from Powers and Brownyard's results, or from the changes in structure that are believed to take place in other inorganic gels during aging [22, 23], wetting and drying [23], or adsorption and desorption of vapors [23]. However, this would not be predicted from the earlier isotherms of Jesser, which indicated that once initial drying shrinkage had taken place, adsorption and desorption of water vapor were reversible [1, 2, 24]. However, some differences between Jesser's experiments and the present ones might be pointed out. He measured comparatively large specimens of low water-cement ratio that were never subjected to vacuum drying. whereas the specimens in the present experiments were broken into small pieces, or even pulverized, and dried in vacuum. Jesser's experiments resemble, to some extent, conditions to which a concrete might be exposed in service, whereas the present experiments and those of Powers and Brownyard employ rather conventional gas sorption techniques [14].

There are a number of mechanisms by which the accessibility of an adsorbent to nitrogen or water vapor might be reduced, and a few examples might be cited. Rao found "drift" in the water-sorption isotherms of titania [25] and ferric oxide [26] gels. He attributed it to coalescence of smaller particles into larger particles, accompanied by a decrease in total capillary volume. An example that may be more closely related to the colloid chemistry of hydrated portland cement is Taylor's evidence [27] that calcium silicate hydrate I, sometimes referred to as tobermorite $[28,29]$, possesses an expanding layer structure similar to that found in some clay minerals. He also found that water-vapor isobars of this compound did not return to their starting point [30], and suggested that this was due to failure of the lattice to reexpand to its original dimensions when brought back to the original conditions of temperature and humidity. Another process by which the surface of an adsorbent might change is polymorphic transformation. Kalousek [31] noted changes in the X-ray pattern of one of his calcium silicate hydrate preparations. Also Brunauer, Copeland, and Bragg [32] reported indications that removal of lime from their tobermorite preparation resulted in formation of small amounts of afwillite. Whatever the mechanism by which the sorptive capacity of hydrated portland cement changes, the present experiments suggest changes in sorptive capacity, and the factors producing these changes are fully as interesting as the surface values themselves.

Another point should be mentioned in connection with the initial drying of hydrated cement paste. If one takes the data shown in figure 4 and plots $v_{m}$

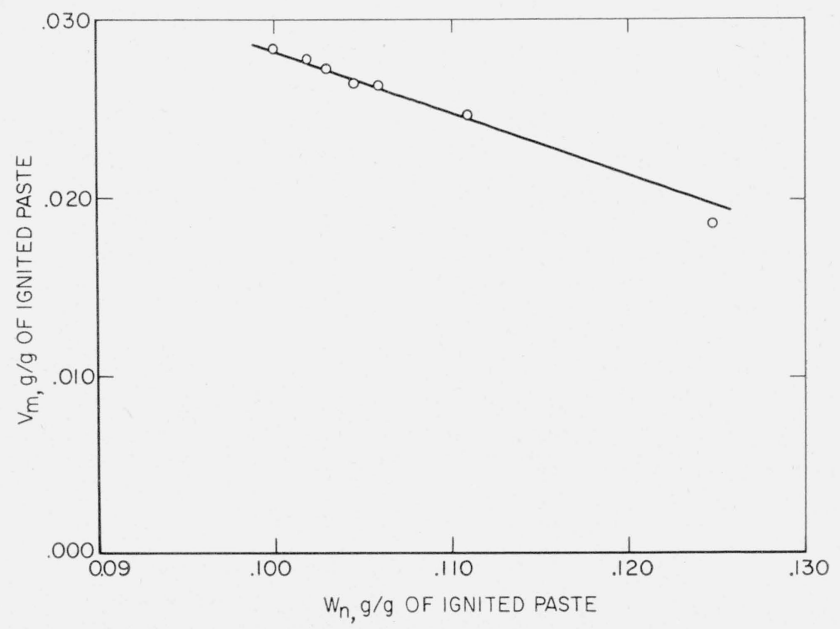

FIGURE 6. $v_{m}$ as a function of nonevaporable water content of a cement paste dried to different levels of dryness. 
as a function of $w_{n}$ as has been done in figure 6 , a linear relationship is obtained. This line differs from the $v_{m} / w_{n}$ plots of Powers and Brownyard [3b], because all of the points have been obtained by drying the same paste for different periods of time, while the plots of Powers and Brownyard were obtained with pastes of different ages which were all dried the same way. The slope of the line in figure 6 is -0.35 , which means that $v_{m}$ increased by $0.35 \mathrm{mg}$ for every milligram of water removed during the latter stages of drying. Expressed as specific surface, $0.35 \mathrm{mg}$ corresponds to $1.2 \mathrm{~m}^{2} / \mathrm{g}$. Copeland and Hayes [9] have pointed out that there is no simple way of calculating a change in $v_{m}$ corresponding to a change in $w_{n}$ produced by a different drying treatment. The linear relationship in figure 6 suggests a possible empirical approach to the problem.

\section{Summary}

Adsorption and desorption of water vapor and repeated wetting and drying resulted in decrease in the water-vapor sorptive capacity of a hardened cement paste. Changes were also produced in the nitrogen sorptive capacity. These results do not preclude the possibility of very small losses of chemically combined water or gains of small amounts of atmospheric contaminants; however, they probably represent shrinkage or other modification of the colloidal structure of cement paste. If surface areas calculated from sorption data are to be treated as functions of the amount of hydration products present, it is important to consider the history of a specimen after hydration has stopped.

The effect of varying the drying time before measuring the nonevaporable water content and surface area by water-vapor adsorption was also considered. When a hardened paste received successively longer drying treatments, a linear relationship between $v_{m}$ and $w_{n}$ was obtained as the paste approached dryness.

The autbors are indebted to T. C. Powers and L. E. Copeland of the Portland Cement Association for many useful suggestions, particularly those relating to the design of equipment for drying cement pastes and measuring water-vapor adsorption. The authors also gratefully acknowledge the assistance of Vernon Dantzler in performing the nitrogenadsorption measurements reported here.

\section{References}

[1] L. Jesser, Kolloidchemische Reaktionen des Tonerdezementmortels, Zement 16, 741 (1927).

[2] S. Giertz-Hedstrom, The physical structure of hydrated cements, Symposium on the Chemistry of Cements (Stockholm, 1938).

[3] T. C. Powers and T. L. Brownyard, Studies in the physical properties of hardened portland cement paste: (a) Part 2, Studies of water fixation, Proc. Am. Concrete Inst. 43, 249 (1946); (b) Part 3, Theoretical interpretation of adsorption data, Proc. Am. Concrete Inst. 43, 469 (1946); also Portland Cement Assoc. Bul. 22 .
[4] L. F. Gleysteen and G. L. Kalousek, A simplified method for the determination of apparent surface area of concrete blocks, Proc. Am. Concrete Inst. 51, 437 (1955).

[5] R. L. Blaine and H. J. Valis, Surface available to nitrogen in hydrated portland cements, J. Research NBS 42, 257 (1949) RP1967.

[6] J. D. Bernal, The structures of cement hydration compounds, Third International Symposium on the Chemistry of Cement, p. 222 (London, 1952). Sec also, appended discussions by Grudemo, p. 247, R. H. Bogue, p. 254, and author's closure, p. 257.

[7] M. Swerdlow, H. F. McMurdie, and F. A. Heckman, Hydration of tricalcium silicate, Proc. Intern. Conf. Electron Microscopy, p. 500 (London, July 1954). Roy. Microscopical Soc. paper No. 119; also Portland Cement Assoc. Fellowship Paper 71.

[8] S. Brunauer, P. H. Emmett, and E. Teller, Adsorption of gases in multimolecular layers, J. Am. Chem. Soc. 60, 309 (1938)

[9] L. E. Copeland and J. C. Hayes, Determination of vonevaporable water in hardened portland cement paste, Am. Soc. Testing Materials Bul. 194, p. 70 (1953); also Portland Cement Assoc. Bul. 47.

[10] T. C. Powers, Nonevaporable water content of hardened portland cement paste-its significance for concrete rasearch and its method of determination, Am. Soc. Testing Materials Bul. 158 (May 1949); also Portland Cement Assoc. Bul. 29.

[11] F. M. Lea, Water in set cement, Cement and Cement Manuf. 5, 395 (1932)

[12] L. E. Copeland and R. H. Bragg, Self desiccation in portland cement pastes, Am. Soc. Testing Materials Bul. 204 , p. 34 (1955).

[13] S. Brunauer, L. E. Copeland, and R. H. Bragg, The stoichiometry of the hydration of tricalcium silicate at room temperature. I. Hvdration in a ball mill, J. Phys. Chem. 60, 112 (1956).

[14] J. W. McBain, The sorption of gases and vapors by solids, p. 23 (G. Routledge \& Sons, Ltd., London, 1932).

[15] R. H. Stokes and R. A. Robinson, Standard solutions for humidity control at $25^{\circ} \mathrm{C}$, Ind. Eng. Chem. 41, 2013 (1949).

[16] P. H. Emmett, A new method for measuring the surface areas of finely divided materials and for determining the size of particles, Symposium on new methods for particle size determination in the subsieve range, Am. Soc. Testing Materials (March 1941).

[17] P. H. Emmett, Gas adsorption methods for measuring surface area of adsorbents, Ind. Eng. Chem. 37, 642 (1945).

[18] H. S. Frey and W. J. Moore, Adsorption of water vapor on glycine, leucine, diketopiperizene, and diglycylglycine, J. Am. Chem. Soc. $\mathbf{8 0}, 3644$ (1948).

[19] M. Dole, Statistical thermodynamics of the sorption of vapors by solids, J. Chem. Phys. 16, 25 (1948).

[20] J. P. Quirk, Significance of surface areas calculated from water vapor sorption isotherms by use of the BET equation, Soil Sci. 80, 423 (1955).

[21] T. C. Powers, A discussion of cement hydration in relation to the curing of concrete, Proc. Highway Res. Bd. 27, 178 (1947); also published as Portland Cement Assoc. Bul. 25.

[22] H. B. Weiser, A textbook of colloid chemistry, p. 316 (John Wiley and Sons, New York, N. Y., 1949).

[23] S. Brunauer, The adsorption of gases and vapors, p. 408 (Princeton Univ. Press, Princeton, N. J., 1945).

[24] F. M. Lea, The chemistry of cement and concrete, p. 223 (St. Martin's Press, Inc., New York, N. Y., 1956).

[25] K. S. Rao, Hysteresis in sorption. I. Permanence of the hysteresis loop, titania gel-water system, J. Phys. Chem. 45, 500 (1941).

[26] K. S. Rao, Hysteresis in sorption. V. Permanence, scanning, and drift of the hysteresis loop, ferric oxide gel-carbon tetrachloride and ferric oxide gel-water systems, J. Phys. Chem, 45, 522 (1941).

[27] H. F. W. Taylor, Hydrated calcium silicates. I. Compound formation at ordinary temperatures, J. Chem. Soc. (London) p. 3682 (1950). 
[28] R. H. Bogue, A note on the nomenclature of the calcium silicate hydrates, Mag. of Concrete Research No. 14, p. 87 (1953); also issued as Portland Cement Assoc. Fellowship Paper 66.

[29] G. P. Claringbull and M. H. Hey, A re-examination of tobermorite, Min. Mag. and J. Min. Soc. 29, 960 (1952).

[30] H. F. W. Taylor, Hydrated calcium silicates. V. The water content of calcium silicate hydrate I, J. Chem. Soc. (London) p. 163 (1953).
[31] George L. Kalousek, Tobermorite and related phases in the system $\mathrm{CaO}-\mathrm{SiO}_{2}-\mathrm{H}_{2} \mathrm{O}$, Proc. Am. Concrete Inst. 51, 989 (1955).

[32] S. Brunauer, L. E. Copeland, and R. H. Bragg, The stoichiometry of the hydration of tricalcium silicate at room temperature. II. Hydration in paste form. J. Phys, Chem. 60, 117 (1956).

WAshington, January 14, 1957. 